\title{
El impacto de las jerarquías de género y edad en las estrategias de movilidad social inter-generacional de familias argentinas y marroquíes en Galicia
}

\author{
Sofía Laíz Moreira \\ LAMES, CNRS - Universitéd’Aix-Marseille,Marseille, France \\ Email:sophialaiz@gmail.com
}

\begin{abstract}
Resumen: El presente artículo tiene por objetivo responder a la pregunta de cómo las jerarquías de género y edad condicionan las trayectorias educativas y profesionales en las migraciones argentinas y marroquíes en Galicia. La investigación que aquí se presenta fue realizada a partir de una metodología cualitativa y multi-situada, aplicando un enfoque de género e inter-generacional. Las reflexiones extraídas ponen de relieve la incidencia de la estructura familiar en las trayectorias estudiadas, cuyos mecanismos de solidaridad y de reciprocidad revelan unas negociaciones concretas entre los géneros y las generaciones.
\end{abstract}

Palabras clave: Migraciones internacionales, movilidad social intergeneracional, jerarquías familiares, género, edad, generación.

\section{The impact of gender and age hierarchies in intergenerational social mobility strategies of argentine and Moroccan families in Galicia}

\begin{abstract}
This paper aims at answering the question of how gender and age hierarchies condition educational and professional trajectories in Argentine and Moroccan migrations in Galicia. The research presented here was carried out using a qualitative and multi-situated methodology, applying a gender and intergenerational approach. The reflections that emerged highlight the impact of the family structure on the trajectories studied, whose mechanisms of solidarity and reciprocity reveal concrete negotiations between the genders and the generations.

Keywords: International migration, intergenerational social mobility, family hierarchies, gender, age, generation.
\end{abstract}




\section{$O$ impacto das hierarquias de gênero e idade nas estratégias de mobilidade social intergeracional das famílias argentinas e marroquinas na Galícia}

Resumo: Este artigo pretende responder à questão de como as hierarquias de gênero e idade condicionam as trajetórias educacionais e profissionais nas migrações argentinas e marroquinas na Galícia. A pesquisa aqui apresentada foi realizada utilizando uma metodologia qualitativa e multi-situada, aplicando uma abordagem de gênero e intergeracional. As reflexões extraídas colocam em destaque a incidência da estrutura familiar nas trajetórias estudadas, cujos mecanismos de solidariedade e reciprocidade revelam negociações concretas entre gêneros e gerações.

Palavras-chave: Migração internacional, mobilidade social intergeracional, hierarquias familiares, gênero, idade, geração.

\section{Introducción}

Estudiar la movilidad social intergeneracional supone incluir una perspectiva de estudio que va más allá de las trayectorias individuales (Sáiz, 2005). El estudio de los procesos de movilidad educativa y ocupacional entre padres e hijos supone, por definición, describir y comprender como las posiciones sociales se transmiten de generación en generación (Thélot, 1991). Erikson y Goldthorpe (1993, p. 301-307) definen el concepto de "estrategias de movilidad" como "las estrategias que conscientemente o no adoptan los individuos y las familias que se encuentran en determinadas posiciones de clase, bien para conservar estas posiciones, bien para mejorarlas” (en Echeverría, 1998, p.72).

Este artículo, como su título lo indica, tiene el propósito de estudiar el impacto de la estructura familiaren las trayectorias migratorias y de movilidad social de un número de familias migrantes asentadas en la Comunidad gallega y de dos orígenes concretos: argentino y marroquí. Para ello, el análisis se centra en el efecto causado por la posición que desempeñan los sujetos dentro del grupo familiar, teniendo en cuenta dos variables: el género y la edad. Su objeto de estudio, por tanto, es el del impacto de las jerarquías familiares o sobre la movilidad social intergeneracional.

Presentar los resultados de los movimientos generacionales dentro de la escala social, es decir, de la mejora de la categoría educativa y profesional (movilidad ascendente) o deterioro (movilidad descendente) de los hijos respecto de la de los padres, no es el objetivo final de este texto, pues su menester es el de analizar cómo las dinámicas intrafamiliares pudieron influir en tales posicionamientos. Para ello partiremos de la premisa (contrastada a partir de las conclusiones generales de esta investigación) de que la migración familiar ha tenido, en efecto, el objetivo de generar una mejora en las condiciones de vida del grupo migrante en su conjunto, si bien ha podido repercutir de forma diferenciada sobre 
sus diferentes miembros, favoreciendo más a unos y perjudicando, quizás, a otros.

El estudio que se presenta en este texto fue realizado entre los años 2011 y 2013 con un grupo de familias migrantes argentinas y marroquíes asentadas en Galicia a comienzos del presente siglo.La elección de esta comunidad autónoma obedece a la característica que la destaca frente a otras regiones españolas también receptoras de estos dos flujos migratorios. Su primer rasgo principal es la relación entre las migraciones argentinas y la reactivación del capital social familiar de "retorno a las raíces” de miembros descendientes de españoles emigrados a este país del cono sur, y en segundo lugar, por las características del entramado socioeconómico y de una pirámide poblacional fuertemente envejecida que ha permitido la creación de dos nichos laborales particulares para la población inmigrada de origen marroquí: el sector de cuidados para las mujeres y el mercado ambulante transnacional instalado en la frontera hispano-lucense.

Teniendo en cuenta los contextos de origen y el momento histórico de las migraciones procedentes de la Provincia de Buenos Aires (Argentina) y de Beni Mellal (Marruecos), establecemos algunos rasgos definitorios que puedan contribuir a contextualizar estos flujos de inmigración hacia Galicia:

Situamos a las familias argentinas en un contexto histórico particular. Se trata de la crisis de principios de siglo XXI y que describe una situación financiera y socio-económica convulsionada que a 1 de diciembre de 2001 culmina con el lanzamiento de la medida conocida como "El corralito”, llamada así al congelamiento de los ahorros privados depositados en los bancos nacionales (Moreno, 2012). Esta medida y el caos social que le siguió, fueron los elementos más importantes que fundamentan la salida casi "masiva” de personas a partir de este año y hasta aproximadamente el año 2005 (Actis y Esteban, 2007; Schmidt, 2009).

El momento socio-histórico que contextualiza la emigración de las familiares marroquíes sitúa aBeni Mellalcomo provincia que encabeza, a finales de los '90, las regiones de salida de flujos migratorios, hecho que guarda estrecha relación con la demanda de mano de obra agrícola desde países como Italia, Francia y España hacia mediados de la década anterior (Berriane, 2004). De esta forma, tal y como ha sucedido con la historia migratoria de Galicia, la provincia de Beni Mellal ha pasado de representar una zona rural por excelencia a una de las principales regiones emisoras de flujos internacionales.

\section{Modelo de análisis, marco teórico y estado de la cuestión}

Hablar de migración y de familia supone referirse a elementos estrechamente conectados (Reist y Riaño, 2008, p. 306). Para indagar en los procesos de movilidad social dentro del grupo familiar y entre las genera- 
ciones resulta imprescindible considerar una visión que entrelace las diferentes expectativas, motivaciones y logros articulados en base a un objetivo común y familiar. Esta premisa se basa en la afirmación de que es la familia, y no las personas, la unidad básica de movilidad social (Sáiz, 2004, p.156).

Esta investigación se propuso articular las esferas de análisis individual y grupal, con el objetivo de estudiar las dinámicas intrafamiliares en las trayectorias migratorias de los grupos migrantes analizados. Para abordar este objetivo, la familia se definió como una meso-unidad de análisis, a la vez que agente social. Este abordaje se entrelaza con otras interpretaciones que conciben el grupo familiar como un entramado de relaciones de poder y que reconocen unos roles familiares pre-establecidos (Grasmuck y Pessar, 1991; Levitt y Schiller, 2004; Pedone, 2004). De esta forma, la familia se erige en tanto nexo conector entre el ámbito de lo macro y de lo micro social, es decir, como campo de negociaciones donde se inserta el actor individual. Dentro de ella, se articularán unas configuraciones de poder dadas y unas jerarquías según género y edad que determinarán las diferentes tensiones y arreglos entre sus miembros. Así, teniendo en cuenta un marco conceptual tridimensional (macro, meso, micro) en el estudio de las migraciones internacionales (Castles 2011, Massey et al. 2008), el hecho de proponer a la unidad familiar como estructura intermedia, ha permitido construir puentes entre los condicionantes micro y macro estructurales.

Debemos destacar que el campo de estudio donde se insertan los resultados que aquí se presentan no profundiza en las grandes teorías clásicas de la movilidad social (Goldthorpe,1980), sino que revisa el marco teórico desarrollado en torno a las trayectorias migratorias de los hijos de inmigrantes a escala nacional e internacional (Portes y Rumbaut, 2001; Zhou, 1997; Alba, 2005; García Borrego, 2008; Portes et al., 2011; Pedreño et al., 2013), tomando los enfoques de los grandes teóricos de la reproducción social (Bourdieu y Passeron, 1970; Bourdieu, 1980; Fernández, 2001) así como la noción de agencia para explicar los procesos de movilidad social de los individuos insertos en unas estrategias familiares. Esta decisión metodológica hace referencia al hecho de centrar nuestro análisis en las diferentes trayectorias de las diferentes generaciones pero, particularmente, del resultado mostrado en la trayectoria de los/ las descendientes como actores claves de la movilidad social familiar dentro del que hemos definido como nuestro objeto de estudio: la familia migrante.

En efecto, la literatura sobre movilidad social intergeneracional en Argentina o en Marruecos, no cuestiona el efecto de las jerarquías de poder dentro de la familia y su efecto sobre los procesos de movilidad social. En Argentina, por ejemplo, los estudios más clásicos (Germani 1965; Jorrat, 2000; Sautu 2003; Salvia 2008; Fernández y Clemenceau 2013), de tipo cuantitativo, no se preocupan por estos aspectos más subjetivos La literatura marroquí sobre la cuestión (Bouasla 2002 y Ben Halimaet al. 2012, Bougroum y Werquin 1995, Ibaaquil 1996, Badimon Emperador 2007), del 
mismo modo, deja bastante de lado el rol de las jerarquías familiares y su impacto sobre la movilidad social intergeneracional.

En Europa, el trabajo de Schmoll en Francia (Schmollet al. 2011a, 2011b) se acerca a un abordaje del tema de las estrategias de movilidad social inter-generacional que prima un análisis cualitativo de la cuestión y Catarino y Morokvasic (2005) lo hacen desde una perspectiva de género.

En España, uno de los pocos trabajos que estudia la movilidad social con un enfoque de género a la vez que transnacional es el de Oso (2007, 2009). Focalizándonos ya en la literatura más específica sobre segundas generaciones de migrantes, destaca el trabajo de Aparicio (Aparicio 2006); sin dejar de mencionar la extensa producción científica de García Borrego (2008, 2012), de Pedreño (Pedreño et al. 2013) o de García Castaño (García Castaño et al. 2013).

Si pasamos al eje de estudio que articula migración, trayectorias migratorias y familia, los últimos trabajos nos llevan a los estudios de Pedone (2004) y de La Spina (2012) que abordan los procesos en los que las formas familiares se adaptan y son adaptadas por los marcos contextuales donde se inserta la migración y por las estrategias diseñadas para lograr los objetivos del proyecto migratorio.

Pese a ello, como vemos, son pocos o inexistentes los estudios que han trabajado el fenómeno de la movilidad social intergeneracional desde un enfoque intra-familiar, es decir, teniendo en cuenta el rol que juega la familia en las estrategias de movilidad social. Este trabajo se propone llenar este vacío dentro de la producción científica sobre migraciones internacionales.

\section{Definición del objeto de estudio y metodología empleada}

El objeto de estudio de esta investigación ha sido la familia migrante, conformada por los cónyuges y sus descendentes. Respecto de la elección de los dos grupos migrantes de estudio, la selecciónobedeció los colectivos estudiados dentro del marco de un proyecto de investigación más amplio, gracias al cual fue posible el estudio comparado de los colectivos argentino y marroquí, particularmente ${ }^{1}$. El contraste entre ambos grupos migrantes hizo aún más tentador el desafío de la comparación. En efecto, resulta importante señalar que, en el caso de las familias marroquíes, el origen social describe unos niveles educativos máximos alcanzados de educación secundaria, en el caso de los padres, y nivel de estudios primarios sin terminar, en el caso de las madres. Este hecho se presenta como un contraste claro frente al origen social de las familias argentinas, todas ellas de origen urbano y de padres pertenecientes a la clase media profesionalizada.

La estrategia metodológica empleada en esta investigación incluyó testimonios de treinta y cuatro familias migrantes, entre ellas, dieciocho de 
origen argentino y dieciséis familias procedentes de Marruecos. Dentro de cada grupo familiar, se han recogido testimonios de al menos dos descendientes y de al menos un progenitor, buscando, a la vez, un equilibro en términos del sexo del entrevistado, priorizando siempre la inclusión de ambos progenitores para permitir un análisis de los roles de género dentro de la estructura familiar.Se recolectaron un total de 171 testimonios entre las diferentes generaciones de migrantes de ambos orígenes nacionales. La técnica escogida fue la entrevista en profundidad, aplicada a diferentes miembros de las diferentes generaciones: la generación de los padres, la de los hijos, y en los casos en los que fue posible, la generación de los abuelos. Esta estrategia metodológica permitió el análisis de los relatos cruzados $^{2}$ incluyendo, además, algunos miembros de las familias que aún residían en el país de origen (Argentina y Marruecos). Solo a partir de un análisis de tipo cualitativo, se podrían conocer las diferentes experiencias de vida de las personas entrevistadas, las diferentes impresiones, los diferentes puntos de vista acerca de un mismo proyecto grupal (el de la migración para la mejora de las condiciones sociales de los descendientes ) y permitirnos explicar un mismo fenómeno social (la movilidad social intergeneracional a partir de la migración) teniendo en cuenta las diferentes voces involucradas y el rol que cada una cumple en este proyecto. Es por ello que en esta investigación todos los relatos fueron relevantes; incluso aquellos de los abuelos y más aun de los miembros de los grupos familiares dejados atrás, pues el diferente enfoque, la diferente perspectiva espacio temporal y generacional pudieron enriquecer la comprensión del fenómeno estudiado.

Daremos lugar, en los párrafos siguientes, a la exposición del análisis de los procesos migratorios conducentes a la movilidad social intergeneracional de cada grupo migrante de forma separada. Para empezar, serán expuestos los resultados del análisis de las trayectorias de las familias argentinas. A continuación, se revelarán los hallazgos obtenidos en el estudio realizado con familias de origen marroquí.

\section{Las migraciones argentinas: la complejidad inter-generacional en el estudio de las migraciones familiares encadenadas}

Si bien existen otros modelos migratorios también recurrentes para el caso de las migraciones procedentes de Argentina, el perfil dominante de los migrantes instalados en Galicia refleja unas migraciones de tipo familiar y grupal, por encima de la migración individual.

El modelo de migración familiar argentino estudiado describe migraciones compuestas, fundamentalmente, por una pareja y sus descendientes. En algunos casos, estas migraciones generacionales incluyen a los abuelos. El destino geográfico de estas familias se sitúa en las provincias gallegas dónde tenían origen las redes de parentesco que vinculaban a 
estos migrantes con Galicia, por lo que muchos se asentaron en las localidades de origen más representativas de la migración gallega en Argentina.

Si realizamos un análisis histórico sobre las relaciones entre este país austral y Galicia, debemos hacer referencia a unas migraciones que proclaman el "retorno", tratándose todas ellas de familias cuyos descendientes estaban vinculados a la migración española del siglo pasado (especialmente, la que tuvo lugar en el período de postguerra - décadas de 1940 y 1950- ). Frente a ello, encontramos el dilema de cómo enmarcar a las diferentes generaciones implicadas en las categorías conocidas de primeras y segundas generaciones de migrantes.

Paradójicamente, estas familias obedecen a generaciones que, en su gran mayoría, no habían conocido Galicia antes de la migración familiar que tuvo lugar a principios de este nuevo siglo. Este fenómeno hace referencia a los llamados "falsos retornados”3 (Oso, Golías y Villares, 2008).

\section{La influencia de la familia en las trayectorias educativas y ocupacionales de las diferentes generaciones argentinas}

Como era de prever, cuando analizamos las dinámicas intrafamiliares en las migraciones estudiadas, descubrimos un entramado de relaciones que funcionan como condicionantes de las trayectorias educativas y ocupacionales de los descendientes. En el caso de las migraciones argentinas, observamos una estructura de poder entre descendientes que tiene su base en unos roles determinados según la variable "edad" más que con cuestiones vinculadas al género de los hijos e hijas. El género parece impactar de forma más rotunda en las trayectorias profesionales de los cónyuges, mostrando diferencias en el sacrificio aportado y en los beneficios obtenidos tras la migración respecto de la trayectoria individual. Veremos, en los siguientes apartados, las características de estos roles dados.

\section{La responsabilidad de los primogénitos y primogénitas}

Los resultados arrojan una conclusión evidente si tomamos la variable "edad" como factor determinante: observamoselabandono del sistema escolar en una instancia más temprana en el caso de los descendientes mayores de la fratria,en contraste con la prolongación de los estudios en el caso de los más jóvenes del grupo. Los y las primogénitas son los que absorbenun mayor peso en la responsabilidad vinculada a la contribución económica al grupo. Este fenómeno ralentiza, en ocasiones, sus propias trayectorias individuales (educativas y profesionales).

No es extraño que la contribución desigual conduzca la desigualdad de oportunidades educativas y, más tarde, profesionales, pues el rol de los y las primogénitos no les permite gozar del mismo apoyo financiero que se otorgará a otros descendientes menores. Este hecho parece guardar rela- 
ción con otro elemento etario condicionante: la edad de llegada al sistema educativo. Los testimonios confirman la influencia del momento de llegada al nuevo ámbito escolar como factor principal de dificultad para el alumnado de origen inmigrante (Rumbaut 1997, Pedreño et al. 2013). El proceso de adaptación a la nueva estructura educativa suele repercutir de manera más directa en aquellos jóvenes llegados en edades más tardías y que se incorporan el sistema escolar gallego hacia el final de la etapa de educación secundaria.

Yo cuando llegué, fue un cambio grande, llegaba con 17 años, tenía toda mi vida allá hecha,...era un método diferente de estudio, además los cursos no eran iguales que allá... tenía gallego... Que no me enteraba absolutamente de nada...El primer trimestre para mí fue horrible, suspendí todas. (Tamara, argentina, 27 años, Vigo, 2012)

La cantidad y calidad del apoyo recibido por los descendientes, por tanto, parece tener como elementos condicionante la edad de llegada a la migración y la posición del sujeto dentro de la fratría. Las historias estudiadas ilustran unas trayectorias escolaresde más larga duración en aquellos descendientes que se incorporaron antes de los 13 años de edad. En efecto, la llegada a una edad más temprana parece garantizar una escolarización más prolongada. Por el contrario, las oportunidades de los primogénitos/as y, en ocasiones, de otros hermanos/as mayores de la fratría estarían ciertamente restringidos por los mecanismos de solidaridad familiar (Pedreño, 2010, p. 349). Una de las consecuencias observadas hace referencia al abandono o postergación de la trayectoria formativa para incorporarse al mercado laboral.

Para comprender cómo se insertan laboralmente estos jóvenes, debemos recordar un contexto socio-económico particular en la Galicia durante la primera década del presente siglo: hacia el año 2008 se comienzan ya a sentir los coletazos de una feroz crisis financiera que toca de lleno la economía española, y que, aunque en una etapa más tardía, sumergirá el mercado de trabajo gallego en una profunda crisis del empleo, especialmente del empleo juvenil.

Si observamos la generación de los padres, las estrategias de inserción al mercado de trabajo muestran una tendencia casi unánime hacia una reconversión profesional conducente al auto-empleo. El fenómeno del autoempleo en las familias migrantes argentinas ha sido ya analizado por Villares (2010) y tuvo como objetivo principal evadir las estructuras de dominación y la discriminación en el mercado laboral. Los primogénitos y primogénitas cumplen un rol fundamental pues contribuyen a la economía del grupo apoyando la actividad emprendida por los padres como estrategia de supervivencia grupal. En algunos casos, son ellos y ellas los que lideran este emprendimiento:

La idea del quiosco fue de mi papa, que me dijo, “mirá cariño acá 
tenés la oportunidad de abrir un quiosco... si querés, trabajalo" (Tamara, 27 años, Vigo, 2012)

Otras veces, la misma estrategia de autoempleo funciona a la vez como alternativa de solución a la falta de empleo juvenil en Galicia. La etnoestratificación y el blindaje de puestos de trabajo dentro del mercado primario por parte de la población local, son otras razones que explican las dificultades de inserción laboral de éstos, fundamentalmente educados en Argentina. Hemos podido constatar que la competencia por cierto tipo de ocupaciones, deja a los jóvenes migrantes en condiciones de mayor precariedad laboral, especialmente cuando no se han continuado los estudios dentro del sistema educativo local y la trayectoria formativa se ha desarrollado mayoritariamente en el país de origen.

Las experiencias analizadas ayudan a comprender las complicaciones familiares que pueden producirse en el proceso de incorporación laboral al nuevo medio social tras la migración. Su consecuencia principal suele ser la interrupción de la trayectoria educativa de uno o varios de los descendientes.Siguiendo los resultados del análisis de las entrevistas recabadas constatamos que este proceso de solidaridad familiar revela que las oportunidades se presentan de forma desigual para los diferentes miembros del grupo familiar, pues las trayectorias individuales dependen de la estrategia que guía al conjunto, cuyo objetivo es sin duda el de la maximización de los recursos con los que cuenta la familia para generar una movilidad social ascendente. Este hecho confirma, una vez más, cómo los objetivos particulares son muchas veces relegados al bienestar del grupo, influyendo de forma más directa en unos miembros que en otros.

De esta forma, los relatos de nuestros informantes confirman que los caminos individuales se encuentran entrelazados con las estrategias familiares. En estos intercambios se suceden numerosas negociaciones sobre los roles establecidos y las aportaciones cedidas al grupo en detrimento de la trayectorias individual, derivando en tensiones entre descendientes "aportadores” y descendientes "beneficiados”. Más aún, la integración de los descendientes en la actividad económica familiar conduce a un aumento del riesgo grupal, pues si bien soluciona la situación de falta de empleo en los más jóvenes, supone una apuesta en la que varios miembros del grupo seconvierten en el medio de subsistencia prioritario de la familia. La actividad familiar puede asimismo contribuir a interrumpir el reciclaje de conocimientos, la formación en Galicia y la iniciativa para buscar otro tipo de puesto en el mercado laboral local y en competencia con los locales. El proceso de reciprocidad se plantea aquí desde los padres hacia los hijos, pues a unos se les contribuye financiándoles los estudios mientras que a otros se les otorga una oportunidad más inmediata de inserción laboral ${ }^{4}$.

Paralelamente al fenómeno de los primogénitos, encontramos una tendencia repetida en los miembros más pequeños del grupo hacia unas trayectorias educativas que parecen no encontrar su fin, congruentes con el contexto de sobre-cualificación generalizado de la juventud en Galicia. 


\section{“Todo por la familia”: madres sacrificadas}

Como ya hemos mencionado, los testimonios muestran que la primera generación, la de los padres, presenta una separación más acusada según roles de género dentro del ámbito familiar. Se evidencian unas estructuras jerarquizadas que posicionan a las madres migrantes dentro de unas trayectorias ocupacionales que relegan lo profesional al ámbito de las responsabilidades dentro del hogar. No es extraño que en la madre recaigan buena parte de los aspectos logísticos y organizativos de la migración grupal, lo que suele bloquear una inserción profesional inmediata a la llegada al nuevo contexto social. Uno de los ámbitos que demanda más inversión en tiempo y dedicación hace referencia a la educación de los hijos, incluyendo la búsqueda y elección del centro escolar, la inscripción en la nueva institución educativa, la asistencia a eventos y reuniones, el apoyo extra-escolar, etc.

Siento que perdí mucho, pero bueno, gané otras cosas, pero si me decís de lo personal o laboral, desde lo personal, yo creo que soy la que salí perdiendo. ... .yo tuve que renunciar a todo, (...).en Argentina me había costado mucho lo que estaba haciendo, estaba mejorando mi puesto laboral. Pero yo no tengo otra familia que mi marido y mis hijos, entonces, era una decisión cerrada. (Dolores, 50 años, Vigo, 2012)

Resulta significativo, sin embargo, la existencia de una minoría de casos en los que estas mujeres han logrado reconducir sus trayectorias profesionales hacia sus ámbitos formativos iniciales. Esta apuesta revela una inversión mucho mayor de tiempo y de recursos. La variable "origen social"5, empero, no parece terminar de explicar estas diferencias, pues en familias con los mismos recursos económicos se suceden diferentes soluciones. Son más bien los roles de género establecidos dentro del ámbito de lo familiar y, sobre todo, las posibilidades de inserción que ofrece la estructura laboral gallega para ellas, los elementos que parecen definir la viabilidad de estas inversiones añadidas en favor de la mujer y madre.

Uno de los grandes obstáculos impuestos desde el marco estructural describe unas políticas que retrasan la reconducción de la trayectoria ocupacional de los progenitores ante la necesidad de realizar largos y tediosos trámites de convalidación de las titulaciones, independientemente de la variable de género:

Parecía todo fabuloso, parecía que yo iba a llegar acá, iba a homologar automáticamente mi título, cosa que no fue así.... Que iba a poder conseguir trabajo rápidamente, cosa que no fue así... En total, habrá tardado dos años el trámite de convalidación, en los que yo no podía ejercer.(Julia, 47 años, O Porriño, 2012)

El impacto de los factores de tipomacro, particularmente de una política migratoria de cupos y de una estructura laboral segmentada entre los géneros en determinados niveles de cualificación, parecen haber influido y 
limitado las posibilidades de empleo femenino de estas familias, pues la integración laboral de las madres con un cierto nivel de cualificación no solo estaba sujeta a lasegregación del colectivo extranjero desde la política de convalidaciones sino que también estaba determinada por las pocas posibilidades de empleabilidad más allá del empleo autónomo como estrategia para escapar a la descualificación laboral, siendo los nichos de empleo destinados al colectivo femenino extranjero en Galicia el sector del care y de la restauración. Es decir, si aplicamos el enfoque de la familia como agencia clave en el proceso de adaptación de los diferentes miembros al nuevo entorno, la mujer parece ceder más que el hombre en favor de los beneficios del grupo y en detrimento de las expectativas personales.

\section{El modelo familiar marroquí y la separación de roles familiares según el género}

La familia marroquí describe una estructura particular, la misma que legitima los derechos, obligaciones y roles dentro del grupo familiar. Los resultados de nuestro trabajo han confirmado, como primer rasgo diferenciador dentro del universo familiar marroquí, una tendencia hacia la fratria polinuclear, como modelo más típico. De esta forma, la idea de familia se basa en familias extensas que configuran verdaderas redes transnacionales. Hemos podido constatar que su estructura no se reduce a las generaciones de padres e hijos, como en el caso argentino, pues en ella se incluyen varios hogares por generación. Los procesos de solidaridad y/ o reciprocidad estudiados se erigen dentro de una red de parentesco que posiciona a los diferentes miembros de la fratría y a sus descendientes, la mayor parte de las veces, dispersos en diferentes contextos sociales.

Cuando analizamos las historias familiares recolectadas a lo largo de los dos años de trabajo de campo realizado en Galicia y en la provincia de Beni Mellal (Marruecos), observamos cómo el papel de los descendientes se divide, tal y como sucede en el caso argentino, en diferentes roles familiares. Los hijos mayores también suelen cubrir una responsabilidad "parental” o "subrogada” (Valenzuela, 1999) que incluye la contribución económica al conjunto familiar. En contrapartida, esta jerarquía incluye factores de género pues otorga a los hermanos varones mayores la potestad de decidir sobre asuntos que conciernen a los descendientes más jóvenes, especialmente a las mujeres de la familia (Pels, 2000). Asimismo, y contrariamente a lo que se observó en el caso argentino, los mayores de la fratría suelen ocupar el rol de tutores o mediadores, ayudando en la articulación de la familia y el sistema escolar, pues cuentan con un mayor dominio del lenguaje que los padres.

Como ya constataron otros autores (Begag, 1988; Poittier, 1993;Boukhobza, 2005) la definición de roles guarda relación con la separación de diferentes esferas donde se ubican a los individuos según tareas "masculinas” o "femeninas” (Dwyer, 1978), según "paternidad” o "maternidad" y en función del orden etario de los descendientes, igualmente jerarquizados por la variable de género. 
Si trabaja en limpieza o así no pasa nada, pero que no trabaje en un en bar o cosas así. (Simo, 20 años, Tui, 2012)

Las hijas son, por ello, posicionadas dentro de un sistema de códigos jerárquicamente instituidos por el padre pero sometidas, en la vida cotidiana, a la vigilancia de su madre y de sus hermanos” (Begag, 1988).

\section{El impacto sobre las trayectorias educativas de los descendientes}

Pese a la estructura familiar marroquí y a la distribución de responsabilidades según el género de los descendientes, parece evidente que la trayectoria educativa de los hijos tiene como principal elemento condicionante, al igual que en el caso argentino, la edad de llegada a la migración. El desconocimiento de las lenguas locales se plantea como obstáculo principal en la adaptación al nuevo contexto escolar, evidenciando unos procesos de integración mucho más complejos que en nuestro otro caso de estudio:

Al venir aquí a los 18 años, olvídate, a los 14 o a los 12 bueno, porque luego tienes más problemas. (Ahlem, 26 años, Vigo, 2012)

Las barreras para la continuación de los estudios para éstos explican la tendencia hacia la vuelta a la actividad tradicional que desarrollan los padres en Galicia (el mercado ambulante):

Mi hermano lo dejó antes. En séptimo o así decidió ponerse de vendedor ambulante, le dijo "mira papá, yo quiero estar contigo; quiero trabajar contigo; quiero ayudarte a ti, tal y cual”. Y nada, empezó a trabajar con mi padre en la venta ambulante. (Ahlem, 26 años, Vigo, 2012)

A pesar de la separación de las esferas productiva y reproductiva según el género, y como ya constataron otros trabajos (Gorard, Rees y Salisbury, 2001) lasniñas describen un nivel educativo mayor que sus hermanos varones, lo que les permite posicionarse de otra forma dentro de esta estructura. Este posicionamiento conlleva una conquista del espacio personal a partir del nivel de cualificación, si bien se trata de un logro amparado por la estrategia de supervivencia familiar.

Las nuevas formas de participación femenina dentro de la estructura de roles familiares se plantea, además, como recurso para escapar de la presión social y control ejercidos por la comunidad co-étnica instalada en las diferentes localidades de asentamiento marroquí en Galicia, que muchas veces influye sobre el tipo de puesto a desempeñar por las niñas

Pese a todo, el desarrollo de unas trayectorias educativas más prolongadas y el logro educativo de en las mujeres comienza a valorarse como parte del éxito del proyecto migratorio familiar. 
El título, da "respeto”. Estatus, algo por el estilo. Prestigio. Poder. Porque dirán “ay, ¡mira lo que estoy haciendo!”, como una forma de llamar la atención. "Mira lo que estoy haciendo, yo puedo hacerlo, voy a llegar a ser ingeniera". Porque la mujer, lo que quiere es libertad, más libertad de la que tiene, el hombre no, lo que quiere es dinero, pasta, un nivel social aceptable, para poder ...esa libertad ya la tienen, no tienen que luchar por ella, sino, fíjate, ellas luchan mucho más para llegar a ser alguien.(Thalía, 23 años, Vigo, 2012)

Con todo, y pese al nivel educativo alcanzado, la consolidación de una movilidad social inter-generacional ascendente se ve limitada por factores de tipo macro, como pueden ser la situación coyuntural del mercado laboral gallego y los procesos de discriminación por origen étnico y/o de género.

\section{Conclusiones}

El análisis desarrollado nos permite extraer conclusiones acerca de la articulación entre la familia, como unidad social de pertenencia del individuo, y el actor migrante, como portador de la acción individual.

La influencia de la familia en las trayectorias educativas y de movilidad ocupacional de los hijos parece mostrar que las estructuras familiares pueden restringir las trayectorias de algunos de sus descendientes y promover las de otros integrantes de la fratria. Hemos visto como la estratificación de los hijos según género y edad para el caso marroquí y según el criterio de edad, únicamente, en el caso argentino, han podido explicar en gran medida el condicionamiento de las acciones individuales articuladas con las posiciones dentro de la estructura familiar de cada descendiente, sin olvidar que cada individuo es dueño de su destino y posee por ello una agencia social que le es innata.

Si en el caso argentino los primogénitos y primogénitas parecen absorber una mayor responsabilidad en habilitar las trayectorias educativas de los hermanos y hermanas menores, en el caso marroquí interfieren además una segregación entre los géneros en el ámbito profesional, siguiendo las expectativas familiares y los mandatos culturales sobre los roles diferenciados de cada género dentro de la esfera de lo familiar pero también trascendiendo a la esfera de lo público, de lo social y de lo laboral.

Más aun, resulta importante señalar que las conclusiones del trabajo de investigación doctoral más amplio en el que se insertan los resultados del presente artículo pusieron de relieve que el impacto de los factores macro sociológicos y, en particular, del mercado laboral gallego, de la crisis económica y de los mecanismos de discriminación por origen nacional y por género, podría predecir aun con más precisión el efecto mejor de ciertas limitaciones impuestas a la movilidad social intergeneracional, . 
Y es que resulta una evidencia que pese a los niveles educativos alcanzados, la segmentación del mercado laboral local según género y etnia se impone como factor que mejor explica una inserción mayoritaria de las jóvenes mujeres; si bien, esta inserción las posicione en los estratos más bajos de la estructura laboral local (sector doméstico y de cuidados, comercio ambulante). Podemos concluir, por todo ello, que la etno-estratificación segmenta el mercado laboral gallego más allá de la formación.

Con todo, la articulación entre estrategias individuales y grupales se orienta a afrontar las problemáticas derivadas de la crisis económica española. Si la optimización de recursos llevará a las familias marroquíes aflexibilizar las exigencias en torno a los sectores ocupacionales de inserción femenina, en el caso de las familias argentinas, el emprendimiento autónomose constituye como recurso estrella de inserción familiar frente al desalentador panorama laboral gallego hacia la segunda década del siglo XXI.

\section{Agradecimientos}

Este artículo es producto de la tesis doctoral de la autora titulada: "Moviendo ficha: jóvenes migrantes, estrategias y trayectorias familiares de movilidad social inter-generacional en las migraciones argentinas y marroquíes a Galicia”, dirigida por Laura Oso Casas y Natalia Ribas Mateos. 


\section{Notas}

${ }^{1}$ Proyecto: "Género, transnacionalismo y estrategias inter-generacionales de movilidad social” (FEM2011-26210)”, Ministerio de Ciencia e Innovación. IP: Oso Casas, Laura.

${ }^{2}$ Esta técnica permitió recabar el testimonio de varias personas de un mismo entorno y sobre el mismo hecho social, para que, a partir de varias voces explicar una misma historia (Pujadas, 1992).

${ }^{3}$ Término que hace referencia a aquellos migrantes, descendientes de la migración gallega de antaño, que se llaman de retorno pero que nunca habían pisado la tierra donde nacieron sus antepasados.

${ }^{4}$ Valenzuela (1999) denominaría “subrogados” a estos primogénitos, pues parecen ocupar un rol parental que permite, a partir de la aportación económica, la continuación y prolongación de las trayectorias educativas de los hermanos menores. Valenzuela establece un orden etario de los descendientes del grupo familiar en diferentes posiciones respecto de la responsabilidad que sustentan dentro de la familia. Mientras los hijos mayores representan la figura "subrogada", contribuyendo al ingreso familiar y con poder de decisión sobre la vida de los hermanos más jóvenes, los hermanos intermedios ejecutarán el rol de "tutores” o “mediadores” en tanto ejercerán de nexo entre el sistema escolar y los padres. Esta categoría es aplicable a familias con lengua materna diferente de la de la sociedad de instalación, como es el caso marroquí, si bien los diferentes roles entre descendientes no se explican únicamente en relación al manejo del idioma.

${ }^{5}$ Los tres elementos que definen el "origen social”, tomando como base la definición realizada por Bourdieu y Passeron (1970), son: el nivel educativo de los padres, la categoría ocupacional y el nivel socio-económico de los padres, y el origen social rural o urbano de procedencia. 


\section{Bibliografía}

Actis, W. y Esteban, F. (2007). Argentinos hacia España (« sudacas » en tierras « gallegas »): el estado de la cuestión. En Novick, S. (Coord.) Sur-Norte: estudios sobre la emigración reciente de argentinos. Buenos Aires, Argentina: Editorial Catálogos.

Alba, R. (2005). Bright vs. blurred boundaries: Second generation assimilation and exclusion in France, Germany, and the United States.Ethnic and Racial Studies, 28, (1), 20-49.

Aparicio, R. (2006). Hijos de inmigrantes que se hacen adultos. Madrid, España: Observatorio Permanente de la Inmigración, Ministerio de Trabajo e Inmigración.

BadimonEmperador, M. (2007). Diplômés chômeurs au Maroc: dynamiques de pérennisation d'une action collective plurielle. L'Année du Maghreb, (III), pp. 297-311.

Begag, A. (1988). Les jeunes filles d’origine maghrébine et les symboliques de la mobilité, Hommes et migrations, (1113), pp. 9-13.

Ben-Halima, B. (2012). Education, Intergenerational Mobility and Inequality. En Hellier, J. y Chusseau, N(eds.). GrowingIncome Inequalities: Economic Analyses, (pp. 107-146). Basingstoke, ReinoUnido: PalgraveMacMillan.

Berriane, M. (2004). La larga historia de las migraciones marroquíes. En López García, B. y Berriane, M. (dirs.) Atlas de la inmigración marroquí en España, (pp. 24-25). Madrid, España: Universidad Autónoma de Madrid.

Bouasla, T. (2002). Auto-emploi et entreprise familiale en milieu urbain au Maroc. Rabat, Marruecos: Université Mohammed V, Faculté des lettres et des sciences humaines.

Bougroum, M. y Werquin, P. (1995). Mobilité et chômage des jeunes diplômés dans la région de Marrakech.Revue région et développement, (1), 139-154.

Bourdieu, P. y Passeron, J.C. (1970). La Reproduction: Éléments d'une théorie du système d'enseignement. Paris, France: Les Editions de minuit.

Bourdieu, P. (1980). Le capital social, Actes de la Recherche en Sciences Sociales, (31), 2-3.

Bourqia, R., El Ayadi, M., El Harras, M. yRachik, H. (2005) Société, Famille, Femmes et Jeunesse: Thematic report for 50 years of 
humandevelopment in Morocco\& perspective 2025, en Belfkih, Meziane.Rapport of Developement Humain «L'avenir se construit et le meilleur est possible».PNUD.

Castles, S. (2011). Migration, crisis, and the global labour market, Globalizations, 8, (3), 311-324.

Catarino, C. y Morokvasic, M. (2005). Femmes, genre, migration et mobilités. Revue européenne des migrations internationales, 21 (1), 7-27.

Dwyer, D. (1978). Ideologies of sexual inequality and strategies for change in male-female relations, American Ethnologist, 5 (2), 227-240.

Fernández, M. (2001). La educación intercultural en la sociedad multicultural.Organización y gestión educativa:Revista del Fórum Europeo de Administradores de la Educación, 9 (6), 3-7.

García Borrego, I. (2008).Herederos de la condición inmigrante: adolescentes y jóvenes en familias madrileñas de origen extranjero, Tesis doctoral inédita. UNED/UAM, Madrid, España.

García Borrego, I. (2012). Las estrategias familiares de reproducción de marroquíes y ecuatorianos en Murcia. En A. García, M. Gadea y A. Pedreño. (eds.)Tránsitos migratorios: contextos transnacionales y proyectos familiares en las migraciones actuales (pp. 171-203). Murcia, España: Editum.

Germani, G. (1965). Laclase como barrera social: Algunos resultados de un test proyectivo. Buenos Aires, Argentina: Centro de Sociología Comparada UBA.

Goldthorpe, J. (1980). Social Mobility and Class Structure in Modem Britain. Oxford, ReinoUnido: Oarendon.

Grasmuck, S. y Pessar, P. (1991). Between two islands: Dominican international migration. California, Estados Unidos: University of California Press.

Jorrat, R. (2010). Logros educacionales y movilidad educacional intergeneracional en Argentina, Revista Desarrollo Económico, 49 (196).

Ibaaquil, L. (1996). L'école marocaine et la compétition sociale: stratégies, aspirations. Rabat, Marrcuecos: Babil.

La Spina, E. (2012). Familias Transnacionales, sociedades multiculturales e integración. España, Italia y Portugal en perspectiva comparada. Madrid, España: Ed. Dykinson. 
Levitt, P. y Schiller, N. (2004).Conceptualizing Simultaneity: A Transnational Social Field Perspective on Society. International Migration Review, 38(3) 1002-1039.

Massey, D.,Arango, J., Hugo, G., Kouaouci, A., Pellegrino, A. y Taylor, E. (2008). Teorías de Migración Internacional: una revisión y aproximación.Revista de Derecho Constitucional Europeo-ReDCE, 5, (10), 435-478.

Moreno,M. (2012).Emigración de argentinos: de la fuga de cerebros a la fragmentación socioeconómica.Coloquio Género y transnacionalismo.A Coruña, España

Oso Casas, L. (coord.) (2007). Trans-cuidadanos: hijos de la migración en Francia. Madrid, España: Ministerio de Trabajo e Inmigración.

(2009). Familia, empresa y movilidad ocupacional: mujeres latinoamericanas en España, Mélanges de la Casa de Velázquez. Nouvellesérie, 39, (1) 75-96.

Oso Casas, L., Golías Pérez, M. y Villares, M. (2008). Inmigrantes extranjeros y retornados en Galicia: la construcción del puente transnacional.Política y sociedad,45 (1), 103-117.

Pedone, C. (2004). Negociaciones en torno al asentamiento definitivo de las familias migrantes ecuatorianas: construcción de espacios sociales trasnacionales. IV congreso sobre la inmigración en España. Universitat de Girona, Gerona, España.

Pedreño Cánovas, A. (2010) Familias inmigrantes: el trabajo de los padres y las estrategias de trabajo de los hijos en las áreas mediterráneas de agricultura intensiva. S. Lara (coord.) Migraciones de Trabajo y movilidad territorial, (pp. 333-367). Ciudad de México, México: Ed. M.A. Porrúa.

(coord.) (2013) “Que no sean como nosotros”. Trayectorias formativo-laborales de los hijos de familias inmigrantes en el campo murciano. Murcia, España: EDITUM

Pels, T. (2000). Muslim Families from Morocco in the Netherlands: Gender Dynamics and Fathers' Roles in a Context of Change. Current Sociology, 48, (4), 75-93.

Portes, A. y Rumbaut, R. (2001). Legacies: The Story of the Immigrant Second Generation.Berkeley, Estados Unidos: University of California Press.

Pujadas, J.J. (1992) El método biográfico: el uso de las historias de vida en ciencias sociales.Madrid, España: Centro de Investigaciones Sociológicas (CIS). 
Reist, D.y Riaño, Y. (2008). Hablando de aquí y de allá: patrones de comunicación transnacional entre migrantes y sus familiares. En G, Herrera y J. Ramírez (eds). América Latina migrante: Estado, familia, identidades,(pp. 303-323). Ecuador, Quito: FLACSO Ecuador.

Rodríguez de la Fuente, J., Fernández, M.C y Clemenceau, C. (2013). Tendencias de movilidad social en la Ciudad de Buenos Aires 20122013: entre ascensos, descensos y reproducción.Ponencia VII Jornadas de Jóvenes Investigadores. Instituto de Investigaciones Gino Germani, Buenos Aires, Argentina.

Rumbaut, R. (1997).Assimilation and its discontents: Between rhetoric and reality. International migrationReview, 31(4), 923-960.

Sáiz López, A. (2004). La migración china en España: Características generales, Revista CIDOB d'afersinternacionals, (68) 151-163.

Salvia, A. (2008). Jóvenes promesas. Trabajo, educación y exclusión social de jóvenes pobres en la Argentina. Buenos Aires, Argentina: Miño y Dávila.

Sautu, R. (2011). El Análisis de las Clases Sociales: Teorías y Métodos. Buenos Aires, Argentina. Ediciones del CCC (Centro Cultural de la Cooperación Floreal Gorini)

Schmidt, S. (2009). De Argentina a España: historias vividas e intercambios imaginados en las migraciones recientes. (Tesis doctoral). Universidad de Salamanca, Salamanca, España.

Schmoll, C., Kofman, E., Kohli, M. y Kraler, A. (2011). Issues and debates on family related migrations and the migrant family: A European perspective. En C. Schmoll, E. Kofman, M. Kohli, y A. Kraler. (dir.). Gender Generation and the Family in International Migration, (pp. 11-52) Amsterdam, PaísesBajos: Amsterdam University Press.

Valenzuela, A. (1999) Gender Roles and Settlement Activities Among Children and Their Immigrant Families, American Behavioral Scientist42 (4) $720-742$

Villares, M. (2010). Inmigración y empresa en Galicia: la movilización diferencial del capital financiero, humano y social (Tesis doctoral). Universidade da Coruña, Galicia, España.

Zhou, M. (1997). Segmented assimilation: Issues, controversies, and recent research on the new second generation, International migration review,special Issue: Immigrant Adaptation and Native-Born Responses in the Making of Americans, 31 (4), 975-1008. 